\title{
BMJ Open Factors contributing to the rapid rise of caesarean section: a prospective study of primiparous Chinese women in Shanghai
}

\author{
Honglei Ji, ${ }^{1,2}$ Hong Jiang, ${ }^{3}$ Limin Yang, ${ }^{4}$ Xu Qian, ${ }^{2}$ Shenglan Tang ${ }^{5}$
}

To cite: Ji H, Jiang $\mathrm{H}$, Yang L, et al. Factors contributing to the rapid rise of caesarean section: a prospective study of primiparous Chinese women in Shanghai. BMJ Open 2015;5:e008994. doi:10.1136/bmjopen-2015008994

- Prepublication history and additional material is available. To view please visit the journal (http://dx.doi.org/ 10.1136/bmjopen-2015008994).

Hong Jiang is the co-first author.

Received 6 June 2015 Revised 22 August 2015 Accepted 9 October 2015

CrossMark

For numbered affiliations see end of article.

Correspondence to

Dr Xu Qian;

xqian@fudan.edu.cn

\section{ABSTRACT}

Objective: To identify factors contributing to the rapid rise of caesarean section in Shanghai through the prospective observation of changes in the preferred mode of delivery in pregnancy among primiparous Chinese women.

Design: Prospective study.

Setting: Two general hospitals in Shanghai.

Participants: A cohort of 832 low-risk primiparous women participated in the investigation from 20102012 three consecutive times, from their second to third trimester and, finally, 1-2 days post partum.

Methods: Participants were interviewed, using standard questionnaires, for information on demographic characteristics, maternal childbirth selfefficacy, their preference of delivery mode before childbirth and on the people most influential to them when making decisions on delivery mode. Caesarean section indications in the medical records were extracted by the investigators and assessed against clinical guidelines. Caesarean sections were categorised into three groups: guideline-defined indications, doctor-defined indications and maternal request.

Main outcome measures: Preferred mode of delivery; indications for caesarean section; actual mode of delivery; determinants of caesarean section.

Results: of 832 pregnant women enrolled, $13.2 \%$ preferred caesarean section in the second trimester. This figure rose to $17.0 \%$ in the third trimester among 599 followed women. Of 523 women completing all three interviews, $58.1 \%$ underwent caesarean section. However, $34.9 \%$ of women undergoing caesarean section did not have any indications listed in the clinical guidelines nor based on maternal request. Multinomial regression analysis showed that doctors' influence was one of the significant risk factors of undergoing caesarean section, with doctor-defined indications. Participants with low maternal childbirth self-efficacy were more likely to request caesarean sections themselves.

Conclusions: When deciding to deliver via caesarean section without justified clinical indications in the guideline, Chinese doctors played an important role in decision-making. Among primiparous Chinese women, decisions to use caesarean sections were often made

\section{Strengths and limitations of this study}

- The uniqueness of our paper is in the use of a prospective study following a number of pregnant women from the second trimester of pregnancy via the third trimester to post partum to identify changes in the preferred mode of delivery in women over the course of pregnancy and to understand the determinants of using caesarean sections for child delivery.

- The pregnant women in the study were selected from only two general hospitals located in one district of Shanghai, and might not reflect the situation in the rest of the country, or even that in the greater metropolitan area of Shanghai.

- A big proportion of loss to follow-up occurred among rural-to-urban migrants.

during the third trimester or during the process of labour.

\section{INTRODUCTION}

Caesarean section (CS) is the most commonly performed surgery in obstetrical care. It can be life-saving and is also a highly effective procedure for preventing complications such as dystocia. The WHO stated, in 2015 , that every effort should be made to provide CS to women in need, rather than striving to achieve a specific rate. ${ }^{1}$ The level of CS rates worldwide varies a great deal. Wylie and Mirza found, from data of 36 developing countries, that the CS rate in the least-developed countries was often $<5 \%$. However, CS appeared to be overused in most-developed countries and emerging economies. The CS rate in those countries stood at more than $30 \% .^{2}$ Other large ecological studies arrived at similar conclusions. $^{3}{ }^{4}$ From 2004 to 2008, the WHO conducted a global survey on maternal and perinatal health with 373 health facilities 
selected from 24 countries across Latin America, Africa and Asia. ${ }^{5}$ Although the data were not nationally representative, China was reported to have the highest CS rate $(46.2 \%)$ in the global survey. ${ }^{6}$ The other countries ranged from $1.62 \%$ (Angola) to $42.0 \%$ (Paraguay). ${ }^{7}{ }^{8} \mathrm{It}$ is worth noting that, in 23 countries, excluding China, the CS rate without medical indications ranged between $0.01 \%$ and $2.10 \%$. In contrast, this figure was $11.6 \%$ in China, accounting for $63 \%$ of all CS without medical indications for the 24 countries surveyed. ${ }^{5}$

The rise in CS rates in middle-income countries, such as Argentina and Paraguay, has been found to be faster in recent decades than that in high-income countries. According to the global survey, Japan had a CS rate of $19.8 \%$ and USA reported a CS rate of $32.8 \%$ in $2012 .{ }^{6} 9$ The average CS rate of 18 European Union member states was $26.8 \%$ in $2011 ;{ }^{10}$ however, China has experienced an exponential increase in CS since the 1980s. ${ }^{11-13}$ From the National Health Service Survey, the overall CS rate has increased rapidly, from $2.35 \%$ to $27.2 \%$, between 1993 and 2008. The CS rates in large Chinese cities with populations over 100 million rose from $10.12 \%$ to $63.0 \%$ between 1993 and 2008 .

The WHO global survey found that CS without medical indications increased the risk of adverse shortterm outcomes. ${ }^{5}$ A secondary analysis of two WHO multicountry surveys showed the importance of avoidance of medically unnecessary primary $\mathrm{CS}^{14}{ }^{14}$ With the introduction of the two-child policy for only-child parents (a policy that allows couples to have two children if one of the parents is an only child) in 2014, avoidance of medically unnecessary primary CS is of special significance in China. In March 2014, the American College of Obstetricians and Gynecologists, and the Society for Maternal-Fetal Medicine, called for policy changes to safely lower the rate of primary caesarean delivery. ${ }^{15}$ This illustrates and supports the need for lowering CS rates at global and at national levels, from a professional perspective.

Researchers have in recent years tried to study factors leading to the rapid increase of CS in China. ${ }^{13}{ }^{16-22}$ The key factors reported included maternal influences of high education and age; provider preference of using CS, overdiagnosis for fetal or maternal risks; and demographic characteristics such as health insurance coverage. Most of the published studies were retrospective, or analysed secondary data or cross-sectional surveys. Given the methodological limitations of these studies, they all failed to understand whether or not these pregnant women wanted CS initially or whether their delivery via CS was due to other factors. Our study aimed to identify factors contributing to the rapid rise of CS in Shanghai through the prospective observation of changes in the preferred mode of delivery (MOD) over the course of pregnancy among primiparous Chinese women. It tried to observe changes in the preference of MOD in different time periods before childbirth, to examine the difference between what was preferred and what actually happened, and to analyse the determinants of changes in the MOD decisions.

\section{METHODS}

\section{Design and study settings}

We used a prospective design to invite a cohort of pregnant women to participate in the three consecutive surveys: the second, third trimester of the pregnancy and 1-2 days after childbirth. The location of the study was in Shanghai, in one of eight central districts in the city. Only two general hospitals in the district provided delivery services-one is a tertiary hospital and the other is a secondary hospital. Both were included in the study as the research sites.

\section{Sample size}

Many factors can be associated with the high CS rates in China. Unable to use all indicators for sample size calculation, we instead took commonly recognised factors reported in the published literature into account for the study sample size. Two sample sizes were calculated based on the proportion of average monthly income per capita and maternal age, ${ }^{23}{ }^{24}$ these were 312 and 532, respectively (type I error was 0.05 and type II error was 0.1 ). We chose the larger sample size and expanded it as we hypothesised that approximately $30 \%$ of women might withdraw from the study. As a result, we came up with a sample of 760 pregnant women for our study.

\section{Data collection}

In Shanghai, most pregnant women receive all their antenatal care in the same hospital where they plan to give birth. From December 2010 to June 2011, pregnant women from the two hospitals who had met the inclusion criteria were asked if they would be willing to participate in the study during their antenatal check-ups. Finally, 832 eligible participants were enrolled consecutively. The selection criteria included: (1) being a primigravida in the second trimester; (2) having no severe heart, liver, lung, kidney or endocrine diseases, and having no history of mental illness (ie, no red labels of high risk on their medical records) and (3) planning to give birth at either of the hospitals included in the study.

In general, the data were collected two ways: information from self-administered questionnaires, including demographic characteristics and maternal preference of MOD, was obtained, and information from medical records, such as body mass index, number of induced abortions undergone, actual MOD, CS indications and the birth weight of the neonate, was extracted by the trained investigators. The standardised questionnaires were designed by the researchers from the School of Public Health of Fudan University. Assessment of maternal self-efficacy on vaginal childbirth, which is the belief of a pregnant woman in her competence to deliver her baby vaginally, was also included in the questionnaires using a validated Chinese scale. ${ }^{25}$ This scale was 
developed, with some modifications, from the General Perceived Self-efficacy Scale (GSES, Ralf Schwarzer) and had a Cronbach's $\alpha$ of 0.81 . The scale scored study subjects' confidence in terms of their personal beliefs in their ability to give birth, their behaviour being based on their own decisions, their ability and confidence to cope with difficulties, and their confidence in delivering babies vaginally. The larger the score, the more confidence the women had to deliver their babies vaginally. ${ }^{25}$ An online additional file 1 shows the detailed components of the scale.

Nurses at the obstetrical clinics and wards were trained to explain the objectives of the survey questionnaires to the participants, to guide them to finish the self-administered questionnaires and to extract necessary information from medical records. The baseline survey was organised immediately after the enrolment, to obtain personal information, maternal self-efficacy on vaginal childbirth and maternal preference of MOD. In the month prior to the expected due date, the nurses interviewed these women again to understand any changes in preferred MOD. After 1 or 2 postpartum days, the participants were interviewed a third time to obtain information about key factors and determinants related to their actual MOD. One of the items in the third questionnaire to affirm key factors was, 'Who was the most influential person in deciding your MOD?'. It was a single-answer question, and the choices included the 'woman herself', 'doctor', 'husband', 'elder members in the family', 'friends' and 'others'.

\section{Adjustment of missing data}

Of the 832 eligible participants who enrolled at the initial stage, $599(72.0 \%)$ completed the second interview and $523(62.9 \%)$ completed the third interview. We investigated the demographic characteristics of the 309 missing participants, and found that many of these women had migrated from rural to urban areas, and did not have permanent residence status in Shanghai (data are given in the first paragraph of Results). In order to study the effect of this exited sample, we estimated its CS rate based on migrant women who completed all three interviews, and adjusted the total CS rate to account for the missing data and their potential accompanying bias. We compared the adjusted CS rate with the true observed CS rate.

\section{Assessment of clinical indications of CS against the guideline}

The study used the national guideline from the 'Clinical Technological Practice Standards-Obstetrics and Gynecology Volume', compiled by the Chinese Medical Association in $2007,{ }^{26}$ to assess if the cases had justified indications for CS. All the CS indications and other information such as estimated birth weight were extracted from medical records as completely as possible. One researcher from Fudan University and one maternal healthcare specialist independently assessed
CS indications, case by case, and discussed the results, using the guideline. If they disagreed with each other, they discussed the disagreements and tried to reach a consensus. If the cases met CS indication criteria, according to the guideline, they were classified as 'guideline-defined indications', while the cases without any medical indications for CS were grouped into 'maternal request'. The remaining cases were classed as 'doctor-defined indications'. For CS with multiple indications, if one indication met the criteria listed in the guideline, the case was deemed as CS with justified indications. Guideline-defined indications mainly comprised of fetal distress, cephalopelvic disproportion, malpresentation and severe pregnancy complications such as eclampsia. However, doctor-defined indications included non-severe pregnancy complications, such as gestational hypertension, oligohydramnios and heavy fetus. The detailed distribution of guideline-defined and doctordefined indications is shown in online additional file 2. The different modes of delivery were broken down accordingly into (1) vaginal delivery (VD), (2) CS on maternal request, (3) CS with doctor-defined indications and (4) CS with guideline-defined indications.

\section{Data management and analysis}

The completed questionnaires were coded by the researchers from Fudan University. The data set was established with double-entry checks using EpiData V.3.1. We used SPSS V.16.0 for statistical analysis. One-way analysis of variance, non-parametric and $\chi^{2}$ tests were used for univariate analyses. A multinomial logistic regression model was established to analyse the factors associated with CS. The dependent variable in the model was the MOD (1=VD, 2=CS on maternal request, 3=CS with doctor-defined indications and $4=\mathrm{CS}$ with guidelinedefined indications). Independent variables included maternal age, residence status, abortion experience, maternal childbirth self-efficacy in the second trimester and the person who most influenced the decision of the MOD. The rationale for choosing these independent variables is described in the Results section.

\section{Quality control}

All the investigators had received proper training prior to the data collection. Every completed questionnaire was double checked by the investigators themselves as well as by the supervisor (ie, team leader). If key questions were not answered, or answers to these questions were inconsistent or not logical, appropriate actions were taken to make corrections by contacting the women again via phone.

\section{Ethical considerations}

All eligible pregnant women were informed of the objectives and contents of the study. A written consent form was signed by the women who agreed to participate in the study. 


\section{RESULTS}

\section{Demographic characteristics of participants}

A total of 832 pregnant women in their second trimester, from the two hospitals, were enrolled at an average of 18.5 gestational weeks (range: 13.1-27.7); of these women, $599(72.0 \%)$ completed the second interview at an average of 37.1 gestational weeks (range: 32.7-41.0). Of the 832 women, $523(62.9 \%)$ completed all three interviews, including 219 women who delivered vaginally and 304 women who had CS procedures (figure 1). Table 1 presents the 523 participants' demographic characteristics. Age and resident status showed statistical differences among four groups. We found that the pregnant women who did not have permanent residence status in Shanghai or who were unemployed, were more likely to drop out of the study. For the women who were lost to the follow-up interviews, $62.1 \%$ did not have Shanghai permanent residence and $29.8 \%$ were unemployed. Other characteristics between those lost to follow-up and those who completed the three interviews differed slightly: average age of lost women was 27.0 versus 27.4 for the followed women; $35.3 \%$ of lost women versus $31.0 \%$ of followed women had induced abortion experience; $12.6 \%$ of lost women versus $13.4 \%$ of followed women preferred CS in the second trimester.

\section{The consistency of physician's decision on CS against guidelines}

As introduced in the Methods section, decisions on the use of CS were assessed, according to the national guideline issued by the Chinese Medical Association. Of 304 women who underwent CS, $15.1 \%$ (46) were based on maternal request, 34.9\% (106) had CS with doctordefined indications and $50.0 \%$ (152) with guidelinedefined indications. Among half of CS that was not decided in line with the guideline, more than two-thirds was decided by doctors and less than one-third of CS was based on maternal request.

\section{Disparity between maternal preference of MOD and actual MOD}

In the second trimester, $13.2 \%$ of the 832 women preferred CS, while in the third trimester this figure rose to $17.0 \%$ of 599 followed women. And, $58.1 \%$ of 523 followed women eventually underwent CS: $8.8 \%$ due to

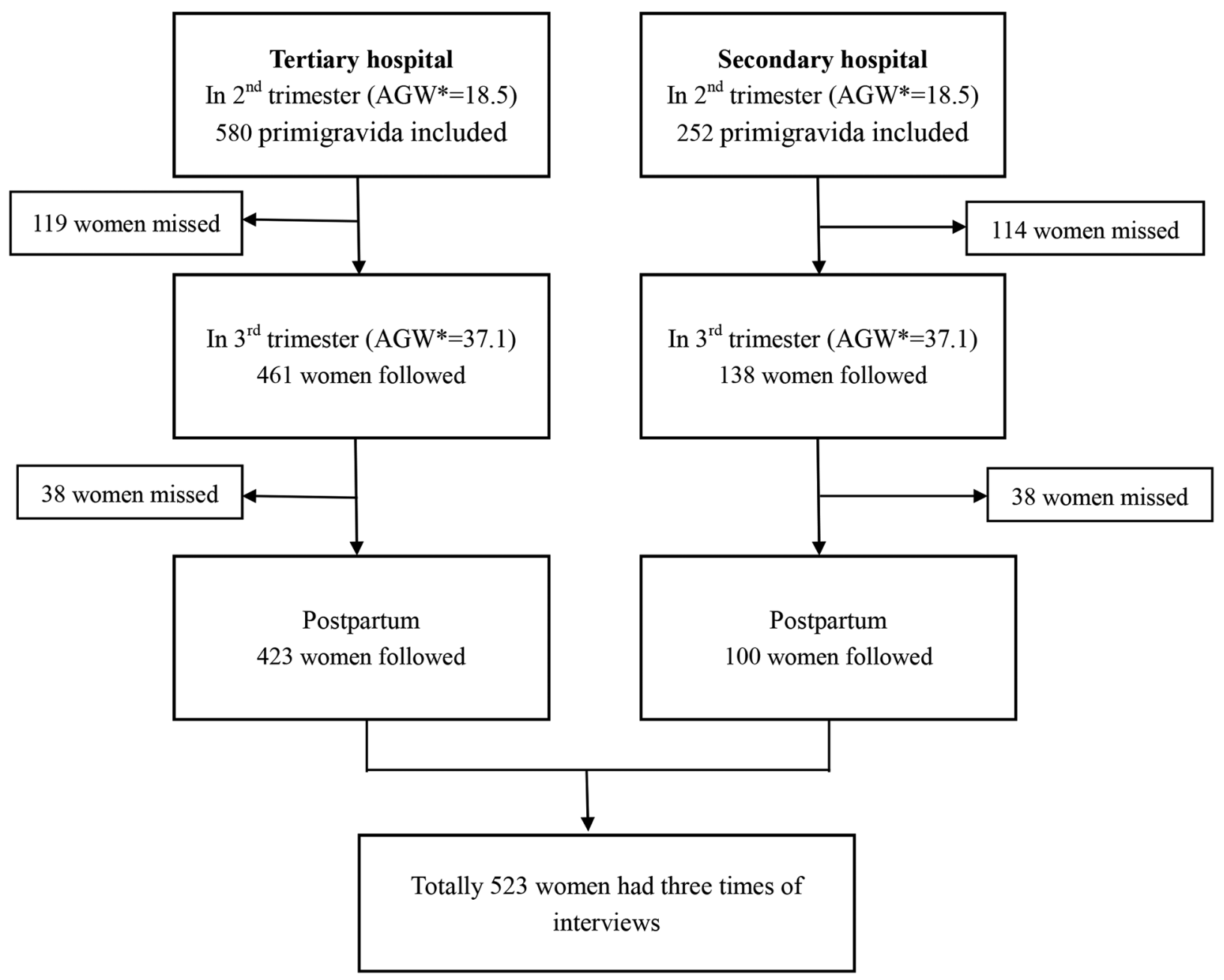

Figure 1 Flow diagram of the cohort in the study. *Average gestational weeks. 
Table 1 Demographic characteristics of primiparous women by mode of delivery $(\mathrm{N}=523)$

\begin{tabular}{|c|c|c|c|c|c|}
\hline & $\begin{array}{l}\text { VD } \\
(\mathrm{N}=219)\end{array}$ & $\begin{array}{l}\text { CS on maternal } \\
\text { request }(\mathrm{N}=46)\end{array}$ & $\begin{array}{l}\text { CS with doctor-defined } \\
\text { indications }(\mathrm{N}=106)\end{array}$ & $\begin{array}{l}\text { CS with } \\
\text { guideline-defined } \\
\text { indications }(\mathrm{N}=152)\end{array}$ & p Value \\
\hline Age & 27.0 & 27.4 & 27.1 & 28.1 & $0.012^{*}$ \\
\hline \multicolumn{5}{|l|}{ Residence status (N (\%)) } & $0.018 \dagger$ \\
\hline $\begin{array}{l}\text { Shanghai residents (with } \\
\text { Shanghai Hukou) }\end{array}$ & $106(37.2)$ & $33(11.6)$ & $64(22.5)$ & $82(28.8)$ & \\
\hline $\begin{array}{l}\text { Migrants (without Shanghai } \\
\text { Hukou) }\end{array}$ & $112(47.5)$ & $13(5.5)$ & $42(17.8)$ & $69(29.2)$ & \\
\hline \multicolumn{5}{|l|}{ Education (N (\%)) } & $0.348 \mp$ \\
\hline Junior high school or lower & $25(51.0)$ & $2(4.1)$ & $9(18.4)$ & $13(26.5)$ & \\
\hline Senior high school & $44(46.3)$ & $8(8.4)$ & $19(20.0)$ & $24(25.3)$ & \\
\hline College level & $137(38.7)$ & $35(9.9)$ & $76(21.5)$ & 106 (29.9) & \\
\hline Master degree or above & $10(45.5)$ & $1(4.5)$ & $2(9.1)$ & 9 (40.9) & \\
\hline \multicolumn{5}{|l|}{ Occupation (N (\%)) } & $0.881 \dagger$ \\
\hline $\begin{array}{l}\text { Worker in factory/ } \\
\text { commercial industry }\end{array}$ & $44(37.6)$ & $8(6.8)$ & $27(23.1)$ & $38(32.5)$ & \\
\hline Private business owner & $21(46.7)$ & $3(6.7)$ & $7(15.6)$ & $14(31.1)$ & \\
\hline Government/technical staff & 101 (42.6) & $21(8.9)$ & $49(20.7)$ & $66(27.8)$ & \\
\hline Unemployed & 43 (43.9) & $12(12.2)$ & $17(17.3)$ & $26(26.5)$ & \\
\hline Others & 5 (29.4) & $2(11.8)$ & $5(29.4)$ & $5(29.4)$ & \\
\hline \multicolumn{5}{|l|}{ Income§ (¥) (N (\%)) } & $0.248 \mp$ \\
\hline$<2000$ & $11(44.0)$ & $4(16.0)$ & $3(12.0)$ & $7(28.0)$ & \\
\hline $2001-4000$ & 77 (43.8) & $7(4.0)$ & $40(22.7)$ & $52(29.5)$ & \\
\hline $4001-5000$ & $41(41.0)$ & $8(8.0)$ & $18(18.0)$ & $33(33.0)$ & \\
\hline$>5000$ & $84(39.6)$ & $26(12.3)$ & $43(20.3)$ & $59(27.8)$ & \\
\hline Childbirth Fees & & & & & $0.103 \dagger$ \\
\hline \multicolumn{6}{|l|}{ Reimbursement } \\
\hline Yes & 157 (39.7) & $40(10.1)$ & 78 (19.7) & $120(30.4)$ & \\
\hline No & $62(48.4)$ & $6(4.7)$ & 28 (21.9) & $32(25.0)$ & \\
\hline \multicolumn{5}{|l|}{ Hospital (N (\%)) } & $0.420 \dagger$ \\
\hline Tertiary & $178(42.1)$ & $38(9.0)$ & $80(18.9)$ & $127(30.0)$ & \\
\hline Secondary & $41(41.0)$ & $8(8.0)$ & $26(26.0)$ & $25(25.0)$ & \\
\hline \multicolumn{6}{|c|}{$\begin{array}{l}\text { *One-way analysis of variance test. } \\
\text { †Pearson } \chi^{2} \text { test. } \\
\ddagger \text { Kruskal-Wallis test. } \\
\text { §Average monthly income per capita. } \\
\text { CS, caesarean section; VD, vaginal delivery. }\end{array}$} \\
\hline
\end{tabular}

maternal request, $20.3 \%$ as a result of doctor-defined indications and $29.1 \%$ as a result of guideline-defined indications, as shown in figure 2. We found the adjusted CS preference rate in the third trimester was $15.3 \%$ and the adjusted CS rate post partum was $56.2 \%: 7.6 \%$ due to maternal request, $19.4 \%$ as a result of doctor-defined indications and $29.2 \%$ as a result of guideline-defined indications. The shift of estimated CS rates due to loss of samples was minimal. In other words, we believe the missing data does not exert a discernible bias.

As seen in table 2, of women who preferred VD in the second trimester, $42.9 \%$ actually delivered their babies vaginally. For those women who preferred VD in the third trimester, $48.1 \%$ delivered vaginally. In comparison, $72.9 \%$ of women who preferred CS in the second trimester and $83.5 \%$ in the third trimester actually underwent CS. Such differences indicate that prenatal CS preference was more closely correlated with actual MOD than VD preference.
Changes in maternal self-efficacy between the second and third trimester

As seen in table 3, the women who opted for CS based on maternal request had the lowest maternal self-efficacy score in both the second and third trimester among the four groups. A difference in self-efficacy scores between the second and third trimester was only found in the group of women having CS with doctor-defined indications.

\section{Analysis of factors contributing to CS rates}

A multinomial logistic regression model was used to analyse factors associated with CS. Among the demographic characteristics of participants we investigated in the study, only age and resident status showed statistical differences (table 1). Education, family income and reimbursement of health service expenses were all highly correlated with the variable of resident status. Thus, we chose only age and resident status in the 


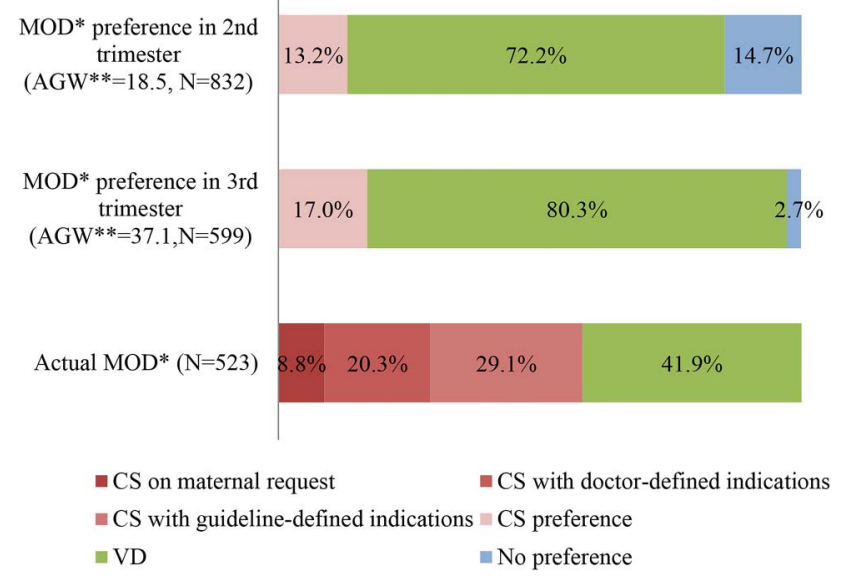

Figure 2 Comparison between actual mode of delivery and maternal preference of mode of delivery prior to childbirth. The actual mode of delivery was divided into four groups: caesarean section on maternal request, caesarean section with doctor-defined indications, caesarean section with guideline-defined indications and vaginal delivery. ${ }^{*}$ Mode of delivery (MOD). ${ }^{* *}$ Average gestational weeks (AGW).

model. Maternal self-efficacy in the second trimester was less likely to be influenced by service providers or selfperceived health status; thus, we included maternal selfefficacy in the second trimester, instead of the third, in the model. This was also the same reason why we only included the maternal MOD preference in the second trimester, and not in the third trimester. Since most participants chose the 'woman herself' and 'doctor' as the most influential person in the postpartum interview, we combined the groups of husband, elder members in the family and friends, into the group of others. The largest variance inflation factor of the variables included in the model was 1.948 , indicating the collinearity of these variables was not severe.
As seen in table 4, maternal childbirth self-efficacy in the second trimester affected CS on maternal request. Along with increases in self-efficacy score, the likelihood of VD increased $1.18(1 / 0.845)$ times compared to CS on maternal request. Maternal preference of CS was only associated with CS on maternal request. Doctor's suggestion on CS decision had an impact on CS with doctor-defined indications and CS with guidelinedefined indications. It appeared to show that doctor's suggestion increased CS with doctor-defined indications and CS with guideline-defined indications but did not influence CS on maternal request. Shanghai residence was a risk factor for CS on maternal request and CS with doctor-defined indications. Abortion experience was another risk factor for only CS with doctor-defined indications. Maternal age was only associated with CS with guideline-defined indications.

\section{DISCUSSION}

The study presented is likely one of the few using a prospective study design to explore factors contributing to the high CS rates among primiparous women in China. One key finding from the study was that most women did not initially want to undergo CS for their delivery but ended up delivering via CS. The changes often took place over 32 gestational weeks and during the process of labour. Doctor's advice on CS was an obvious factor for CS without those listed indications in the guideline. Lower maternal self-efficacy for childbirth might be a key determinant for CS on maternal request. More women with a Shanghai resident certificate (Hukou) ended up as pregnancy with CS than did women who were migrants living in Shanghai. Maternal age was found to only be associated with CS with guideline-defined indications.

One main finding from our study is that the CS with doctor-defined indications accounted for $34.9 \%$ of the

Table 2 Comparison of actual MOD with antenatal maternal preference MOD ( $N=523)$

\begin{tabular}{|c|c|c|c|c|c|c|c|c|}
\hline & \multicolumn{3}{|c|}{ MOD preference in 2nd trimester* } & \multirow[b]{2}{*}{ p Value } & \multicolumn{3}{|c|}{ MOD preference in 3rd trimestert } & \multirow[b]{2}{*}{ p Value } \\
\hline & $\begin{array}{l}\text { VD (N } \\
(\%))\end{array}$ & $\begin{array}{l}\text { CS (N } \\
(\%))\end{array}$ & $\begin{array}{l}\text { No } \\
\text { Preference } \\
(\mathrm{N}(\%))\end{array}$ & & $\begin{array}{l}\text { VD (N } \\
(\%))\end{array}$ & $\begin{array}{l}\text { CS (N } \\
(\%))\end{array}$ & $\begin{array}{l}\text { No } \\
\text { preference } \\
(\mathrm{N}(\%))\end{array}$ & \\
\hline \multicolumn{4}{|l|}{ Actual MOD } & \multirow[t]{6}{*}{$0.007 \ddagger$} & & & & \multirow[t]{6}{*}{$<0.001 \ddagger$} \\
\hline VD & $161(42.9)$ & $19(27.1)$ & $39(50.0)$ & & $201(48.1)$ & $15(16.5)$ & $3(21.4)$ & \\
\hline Total CS & $214(57.1)$ & $51(72.9)$ & $39(50.0)$ & & $217(51.9)$ & $76(83.5)$ & $11(78.6)$ & \\
\hline CS on maternal request & $25(6.7)$ & $13(18.6)$ & $8(10.3)$ & & $20(4.8)$ & $26(28.6)$ & 0 & \\
\hline $\begin{array}{l}\text { CS with doctor-defined } \\
\text { indications }\end{array}$ & $81(21.6)$ & $13(18.6)$ & $12(15.4)$ & & $76(18.2)$ & $25(27.5)$ & $5(35.7)$ & \\
\hline $\begin{array}{l}\text { CS with } \\
\text { guideline-defined } \\
\text { indications }\end{array}$ & $108(28.8)$ & $25(35.7)$ & $19(24.4)$ & & $121(28.9)$ & $25(27.5)$ & $6(42.9)$ & \\
\hline $\begin{array}{l}{ }^{*} \text { Average gestational weeks: } 1 \\
\text { †Average gestational weeks: } 3 \\
\ddagger p \text { Values of Pearson } \chi^{2} \text { test in } \\
\text { and CS with guideline-defined } \\
\text { CS, caesarean section; MOD, }\end{array}$ & $\begin{array}{l}\text { range: } 13.1 \\
\text { range: } 32.7 \\
\text { OD preferen } \\
\text { cations. } \\
\text { de of delive }\end{array}$ & $\begin{array}{l}7.7 . \\
1.0 . \\
\text { s among } \\
\text { VD, vagin }\end{array}$ & $\begin{array}{l}\text { nen of } \mathrm{VD}, \mathrm{c} \\
\text { delivery. }\end{array}$ & rean or & ternal req & t, CS with & ctor-defined i & ations \\
\hline
\end{tabular}


Table 3 Changes of maternal self-efficacy between the second and the third trimester by different MOD

\begin{tabular}{llllr}
\hline & $\begin{array}{l}\text { Score of SE in } \\
\text { 2nd trimester* } \\
\text { Median }\left(\mathbf{P}_{\mathbf{2 5}}-\mathbf{P}_{\mathbf{7 5}}\right)\end{array}$ & $\mathbf{p}$ Value & $\begin{array}{l}\text { Score of } \mathbf{S E} \text { in } \\
\text { 3rd trimestert } \\
\text { Median }\left(\mathbf{P}_{\mathbf{2 5}}-\mathbf{P}_{\mathbf{7 5}}\right)\end{array}$ & $\mathbf{p ~ V a l u e ~}$ \\
\hline Actual MOD & & $<0.001 \ddagger$ & & $<0.001 \ddagger$ \\
VD & $16.0(13.0-19.0)$ & & $15.0(14.0-19.0)$ & $0.350 \S$ \\
CS on maternal request & $13.0(10.5-15.0)$ & & $12.0(10.0-15.0)$ & $0.575 \S$ \\
CS with doctor-defined indications & $16.0(13.0-19.0)$ & & $15.0(11.0-17.0)$ & $0.009 \S$ \\
CS with guideline-defined indications & $15.0(13.0-18.0)$ & & $15.0(13.0-17.0)$ & $0.512 \S$ \\
\hline
\end{tabular}

*Score of self-efficacy in average gestational weeks: 18.5 , range: $13.1-27.7$.

†Score of self-efficacy in average gestational weeks: 37.1 , range: $32.7-41.0$

$\ddagger \mathrm{p}$ Values of Kruskal-Wallis test in maternal self-efficacy among women of VD, caesarean on maternal request, CS with doctor-defined indications and CS with guideline-defined indications.

$\S p$ Values of Wilcoxon signed-rank test in the changes of maternal self-efficacy between the second and the third trimester by different MODs. $\mathrm{CS}$, caesarean section; MOD, modes of delivery; VD, vaginal delivery.

total number of CS cases. This illustrates that about one-third of the CS cases did not have CS indicators defined by the guideline or were not based on maternal requests. These cases were due largely to the loosening of criteria by doctors. The results from the analysis of the person who most influenced MOD in the multinomial logistic model support this argument. This finding on CS influenced by doctors is consistent with findings of other recent studies published..$^{2021} 27$ Gao et $a l^{20}$ reported that the overdiagnosis of fetal and maternal risks was the key determinant of high rates of CS in
China, rather than maternal requests. Feng $e t a l^{21}$ concluded that structural factors relating to service supply had greater impacts on rising CS rates than other demographic characteristics, including the household's willingness and ability to pay. A retrospective study in Shanghai found that a suggestion from the doctor was a strong predictor for $\mathrm{CS}^{27}$ The rising rate of $\mathrm{CS}$, after the introduction of market mechanisms in health system reform, ${ }^{28}$ might be attributed to perverse financial incentives associated with fee-for-service payment, increasing reliance on user charges to recouple the

Table 4 Multinomial logistic statistical analysis for actual CS

\begin{tabular}{|c|c|c|c|c|c|c|}
\hline & \multicolumn{2}{|c|}{ CS on maternal request } & \multicolumn{2}{|c|}{$\begin{array}{l}\text { CS with doctor-defined } \\
\text { indications }\end{array}$} & \multicolumn{2}{|c|}{$\begin{array}{l}\text { CS with guideline-defined } \\
\text { indications }\end{array}$} \\
\hline & Crude OR & $\begin{array}{l}\text { Adjusted OR } \\
(95 \% \mathrm{Cl})\end{array}$ & $\begin{array}{l}\text { Crude } \\
\text { OR }\end{array}$ & $\begin{array}{l}\text { Adjusted OR } \\
(95 \% \mathrm{Cl})\end{array}$ & $\begin{array}{l}\text { Crude } \\
\text { OR }\end{array}$ & $\begin{array}{l}\text { Adjusted OR } \\
(95 \% \mathrm{Cl})\end{array}$ \\
\hline $\begin{array}{l}\text { Self-efficacy in 2nd } \\
\text { trimester }\end{array}$ & $0.845^{\star}$ & 0.845 (0.771 to 0.926$)$ & 1.001 & 0.990 (0.923 to 1.062$)$ & 0.969 & 0.981 (0.921 to 1.044$)$ \\
\hline \multicolumn{7}{|c|}{ Who mostly influenced MOD† decision } \\
\hline Woman herself (ref) & 1 & 1 & 1 & 1 & 1 & 1 \\
\hline Doctor & 0.503 & $0.483(0.131$ to 1.788$)$ & $2.525^{\star}$ & 2.504 (1.307 to 4.796$)$ & $2.129^{\star}$ & 2.239 (1.222 to 4.102$)$ \\
\hline Others $\ddagger$ & 0.641 & $0.640(0.236$ to 1.734$)$ & 0.541 & 0.417 (0.177 to 0.921$)$ & $0.314^{\star}$ & $0.382(0.180$ to 0.810$)$ \\
\hline \multicolumn{7}{|c|}{ Preference of MOD in 2 nd trimester } \\
\hline No preference & $0.300^{*}$ & $0.510(0.164$ to 1.583$)$ & 0.450 & $0.457(0.162$ to 1.286$)$ & $0.370^{*}$ & $0.372(0.154$ to 0.900$)$ \\
\hline VD preference & $0.227^{\star}$ & $0.345(0.140$ to 0.850$)$ & 0.735 & 0.809 (0.357 to 1.830$)$ & 0.510 & 0.519 (0.256 to 1.052$)$ \\
\hline CS preference (ref) & 1 & 1 & 1 & 1 & 1 & 1 \\
\hline Age & 1.040 & 1.021 (0.914 to 1.140$)$ & 1.006 & 0.980 (0.904 to 1.063$)$ & $1.106^{*}$ & $1.087(1.012$ to 1.167$)$ \\
\hline \multicolumn{7}{|c|}{ 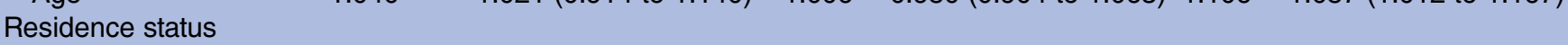 } \\
\hline $\begin{array}{l}\text { Shanghai residents } \\
\text { (with Shanghai Hukou) }\end{array}$ & $2.682^{*}$ & 2.758 (1.245 to 6.109$)$ & $1.610^{\star}$ & 1.749 (1.036 to 2.953$)$ & 1.256 & $1.100(0.692$ to 1.747$)$ \\
\hline Migrants (without & 1 & 1 & 1 & 1 & 1 & 1 \\
\hline \multirow{2}{*}{\multicolumn{7}{|c|}{$\begin{array}{l}\text { Shanghai Hukou to ref) } \\
\text { Number of induced abortions }\end{array}$}} \\
\hline & & & & & & \\
\hline 0 (ref) & 1 & 1 & 1 & 1 & 1 & 1 \\
\hline 1 & 1.786 & 1.868 (0.815 to 4.285$)$ & $1.910^{\star}$ & $1.992(1.0903640)$ & 1.424 & $1.382(0.790$ to 2.416$)$ \\
\hline 2 or more & 1.767 & $3.106(0.908$ to 10.623$)$ & $2.352^{\star}$ & 3.138 (1.317 to 7.476$)$ & 1.435 & 1.481 (0.634 to 3.461$)$ \\
\hline
\end{tabular}


operational costs of healthcare, and the linkage between revenue generation and the income of Chinese doctors. This hypothesis is in accordance with studies ${ }^{29} 30$ in south Asian communities and Western Australia, which found that the increased CS rates may be driven in part by the private sector, due to strong financial incentives for surgical procedures in that sector.

Another possible factor driving the rise of CS rates in China could be doctors' avoidance of potential practice risks. Shanghai introduced and has implemented the Maternal Death Audit System (MDAS) for almost 20 years. ${ }^{31}$ Any maternal death case reported is reviewed and assessed by the system, which has put much pressure on each hospital in Shanghai. If the maternal death is categorised as type 1 (ie, avoidable) or type 2 (ie, missed opportunities) by the MDAS, the related health staff, managers and leaders receive disincentives. Therefore, doctors try their best to prevent maternal deaths, which may lead to their overactions towards any potential risks related to childbirth. At present, the relationship between doctors and patients in China is very tense, resulting in doctors being extra prudent. ${ }^{32}$ As a consequence, many unnecessary CS procedures might be a response to such pressures. The practice in other countries of taking concerted actions to lower CS rates ${ }^{33}$ should be adopted by China. According to the new guideline from the International Federation of Gynecology and Obstetrics, mother-baby 'friendly' birthing facilities might also be helpful in further improving quality care during labour and in lowering unnecessary CS procedures. ${ }^{34}$

Our findings on maternal self-efficacy revealed that low maternal self-efficacy was a key determinant of maternal request for CS. Self-efficacy was defined by Bandura, ${ }^{35}$ in 1977 , as confidence that one can successfully execute a course of action to produce a desired outcome in a given situation. Women's self-efficacy in childbirth is a strong, well-studied influencing factor, particularly in developed countries, since the 1990s. ${ }^{36}$ However, studies on CS carried out in mainland China have rarely examined the possible impact of self-efficacy on the MOD. We found that higher maternal childbirth self-efficacy in the second trimester could lower CS on maternal request. In other words, CS on maternal request might relate to the level of women's confidence. Increasing maternal self-efficacy on childbirth would reduce maternal requests for CS.

In our study, maternal age was found to be associated with CS with guideline-defined indications, which was not surprising. Our study did not find the relationship of education levels and insurance coverage to be associated with MOD, unlike what many previously published studies reported. One possible reason is that a majority of the participants in our study were relatively homogeneous, that is, having higher education training (eg, more than $68.0 \%$ had at least a college degree) and having a high percentage of insurance.

Our study has a few limitations. First, the study's pregnant women were selected from only two general hospitals located in one district of Shanghai, and might not reflect the situation in the rest of the country, or even that in the greater metropolitan area of Shanghai. Second, many women, mainly from the group of rural-to-urban migrants, dropped out during the study, as they decided to return to their hometown for delivery. However, we think such a problem would not affect the results significantly, as we used the data of other migrant women to replace the missing data and found the adjusted CS preference rate in the third trimester as $15.3 \%$ and the adjusted CS rate post partum as $56.2 \%$, which were slightly lower than the actual rates $(17.0 \%$ and $58.1 \%$ ). And the rate of CS among the study population was $58.1 \%$ - very similar to the total CS rate of the two hospitals, $55.3 \%$, in the study year 2011 .

\section{CONCLUSIONS}

In short, our study shows that Chinese doctors play an important role in the decision of using CS, without justified indications as defined in the guideline. A decision on the use of CS was often made during the third trimester of the pregnancy or during the process of labour. Low maternal childbirth self-efficacy was also a significant risk factor associated with maternal request for CS among primiparous Chinese women. Concerted action targeting service providers as well as users needs to be taken in the near future, in order to effectively control the rapid rise of CS in China.

\section{Author affiliations}

${ }^{1}$ Department of Epidemiology and Social Science, Shanghai Institute of Planned Parenthood Research/WHO Collaborating Center for Research in Human Reproduction, Shanghai, China

${ }^{2}$ Department of Maternal, Child and Adolescent Health, School of Public Health and Global Health Institute, Fudan University, Shanghai, China ${ }^{3}$ Department of Maternal, Child and Adolescent Health, School of Public Health and Key Laboratory of Public Health Safety (Ministry of Health), Fudan University, Shanghai, China

${ }^{4}$ Maternity and Child Health Institution of Zhabei District, Shanghai, China ${ }^{5}$ Duke Global Health Institute, Duke University, Durham, North Carolina, USA

Acknowledgements The authors would like to thank Ms Rae Tang for her contribution in preparing the manuscript and Ms Kaori Sato for editing and formatting the paper. They thank Professor Naiqing Zhao from Fudan University and Dr Xuan Che from the National Institute of Health, USA, provided technical support in the analysis of data. They also thank to the doctors and staff from the study hospitals in Shanghai, China, for their generous support in the implementation of the study on which this paper was written.

Contributors $X Q$ designed and led the study, and was responsible for data collection and analysis, and manuscript writing. HJi participated in project design, data collection and analyses, and manuscript preparation. HJia participated in the project design and manuscript preparation. LY was involved in the project design and data collection. ST contributed to data analysis and finalised the manuscript.

Funding The study was supported by Shanghai Zhabei Health Bureau and China Medical Board grant 13-131 of Global Health Institute, Fudan University.

Competing interests None declared.

Ethics approval The study was approved by the Ethics Committee at the School of Public Health, Fudan University. 
Provenance and peer review Not commissioned; externally peer reviewed.

Data sharing statement No additional data are available.

Open Access This is an Open Access article distributed in accordance with the Creative Commons Attribution Non Commercial (CC BY-NC 4.0) license, which permits others to distribute, remix, adapt, build upon this work noncommercially, and license their derivative works on different terms, provided the original work is properly cited and the use is non-commercial. See: http:// creativecommons.org/licenses/by-nc/4.0/

\section{REFERENCES}

1. World Health Organization. WHO Statement on Caesarean Section Rates, 2015.

2. Wylie BJ, Mirza FG. Cesarean delivery in the developing world. Clin Perinatol 2008;35:571-82, xii.

3. Betrán AP, Merialdi M, Lauer JA, et al. Rates of caesarean section: analysis of global, regional and national estimates. Paediatr Perinat Epidemiol 2007;21:98-113.

4. Cavallaro FL, Cresswell JA, França GV, et al. Trends in caesarean delivery by country and wealth quintile: cross-sectional surveys in southern Asia and sub-Saharan Africa. Bull World Health Organ 2013;91:914-22D.

5. Souza JP, Gülmezoglu A, Lumbiganon $P$, et al. Caesarean section without medical indications is associated with an increased risk of adverse short-term maternal outcomes: the 2004-2008 WHO Global Survey on Maternal and Perinatal Health. BMC Med 2010:8:71.

6. Lumbiganon P, Laopaiboon M, Gülmezoglu AM, et al., World Health Organization Global Survey on Maternal and Perinatal Health Research Group. Method of delivery and pregnancy outcomes in Asia: the WHO global survey on maternal and perinatal health 2007-08. Lancet 2010;375:490-9.

7. World Health Organization. Rising caesarean deliveries in Latin America: how best to monitor rates and risks, 2009.

8. Shah A, Fawole B, M'Imunya JM, et al. Cesarean delivery outcomes from the WHO global survey on maternal and perinatal health in Africa. Int J Gynaecol Obstet 2009;107:191-7.

9. Hamilton BE, Martin JA, Ventura SJ. Births: preliminary data for 2012. Natl Vital Stat Rep 2013;62:1-20.

10. http://data.euro.who.int/hfadb/.

11. Wang $\mathrm{LH}$, Zhao GL, Bao YQ, et al. An analysis on changing trend of primiparaous cesarean section rates and indications in 25 years. Chin J Perinat Med 1998;1:9-12.

12. Zhu LP, Qin M, Shi DH, et al. Investigation of cesarean section in Shanghai and effect on maternal and child health. Matern Child Health Care China 2001;16:763-4.

13. Cai WW, Marks JS, Chen $\mathrm{CH}$, et al. Increased cesarean section rates and emerging patterns of health insurance in Shanghai, China Am J Public Health 1998;88:777-80.

14. Vogel JP, Betrán AP, Vindevoghel N, et al., WHO Multi-Country Survey on Maternal and Newborn Health Research Network. Use of the Robson classification to assess caesarean section trends in 21 countries: a secondary analysis of two WHO multicountry surveys. Lancet Glob Health 2015;3:e260-70.

15. Caughey AB, Cahill AG, Guise JM, et al., American College of Obstetricians and Gynecologists (College); Society for Maternal-Fetal Medicine. Safe prevention of the primary cesarean delivery. Am J Obstet Gynecol 2014;210:179-93.
16. Tang S, Li X, Wu Z. Rising cesarean delivery rate in primiparous women in urban China: evidence from three nationwide household health surveys. Am J Obstet Gynecol 2006;195:1527-32.

17. Klemetti $\mathrm{R}$, Che $\mathrm{X}, \mathrm{Gao} \mathrm{Y}$, et al. Cesarean section delivery among primiparous women in rural China: an emerging epidemic. $A m \mathrm{~J}$ Obstet Gynecol 2010;202:65.e1-6.

18. Bogg L, Huang $\mathrm{K}$, Long $\mathrm{Q}$, et al. Dramatic increase of Cesarean deliveries in the midst of health reforms in rural China. Soc Sci Med 2010;70:1544-9.

19. Huang K, Tao F, Faragher B, et al. A mixed-method study of factors associated with differences in caesarean section rates at community level: the case of rural China. Midwifery 2013;29:911-20.

20. Gao $Y$, Xue $Q$, Chen $G$, et al. An analysis of the indications for cesarean section in a teaching hospital in China. Eur J Obstet Gynecol Reprod Biol 2013;170:414-18.

21. Feng $\mathrm{XL}, \mathrm{Xu} \mathrm{L}, \mathrm{Guo} \mathrm{Y}$, et al. Factors influencing rising caesarean section rates in China between 1988 and 2008. Bull World Health Organ 2012;90:30-9, 39A.

22. Long $Q$, Klemetti $R$, Wang $Y$, et al. High Caesarean section rate in rural China: is it related to health insurance (New Co-operative Medical Scheme)? Soc Sci Med 2012;75:733-7.

23. Liu L, Jiang XQ, Wang J, et al. Investigation on influencing factors of cesarean section rate in Chongqing. Matern Child Health Care China 2009;24:98-9.

24. Zhang Y. The determinants of high Caesarean Section rate in Shanghai. Fudan University, 2007.

25. Yang TZ. Health behavior theory and research. Beijing: People's Medical Publishing House, 2007.

26. Chinese Medical Association. Clinical technological practice standards/obstetrics and gynecology volume. Beijing: People's Military Medical Press, 2007.

27. Deng W, Klemetti R, Long Q, et al. Cesarean section in Shanghai: women's or healthcare provider's preferences? BMC Pregnancy Childbirth 2014;14:285.

28. Arrieta A. Health reform and cesarean sections in the private sector: the experience of Peru. Health Policy 2011;99:124-30.

29. Neuman M, Alcock G, Azad K, et al. Prevalence and determinants of caesarean section in private and public health facilities in underserved South Asian communities: cross-sectional analysis of data from Bangladesh, India and Nepal. BMJ Open 2014;4:e005982.

30. Einarsdóottir K, Haggar F, Pereira G, et al. Role of public and private funding in the rising caesarean section rate: a cohort study. BMJ Open 2013;3:pii: e002789.

31. Zhu LP, Jia WL, Cheng XM. Measures and results of quality management in obstetrics in Shanghai. Chin J Hosp Admin 2006;22:167-9.

32. Yang LM, Ji HL, Yang LL, et al. Qualitative study of the effect of health service providers and health care system on high cesarean section rate in Zhabei District of Shanghai. Chin $J$ Woman Child Health Res 2013;24:854-6.

33. Ayres-De-Campos D, Cruz J, Medeiros-Borges C, et al. Lowered national cesarean section rates after a concerted action. Acta Obstet Gynecol Scand 2015;94:391-8.

34. International Federation of Gynecology and Obstetrics, International Confederation of Midwives; White Ribbon Alliance; International Pediatric Association; World Health Organization; International Federation of Gynecology And Obstetrics. Mother-baby friendly birthing facilities. Int J Gynaecol Obstet 2015;128:95-9.

35. Bandura A. Self-efficacy: toward a unifying theory of behavioral change. Psychol Rev 1977;84:191-215.

36. Crowe $\mathrm{K}$, von Baeyer $\mathrm{C}$. Predictors of a positive childbirth experience. Birth 1989;16:59-63. 